\title{
A new mathematical model for horizontal wells with variable density perforation completion in bottom water reservoirs
}

\author{
Dian-Fa Du ${ }^{1} \cdot$ Yan-Yan Wang $^{2} \cdot$ Yan-Wu Zhao ${ }^{1} \cdot$ Pu-Sen Sui $^{3} \cdot \mathrm{Xi} \mathrm{Xia}^{1}$
}

Received: 11 July 2016/Published online: 12 April 2017

(c) The Author(s) 2017. This article is an open access publication

\begin{abstract}
Horizontal wells are commonly used in bottom water reservoirs, which can increase contact area between wellbores and reservoirs. There are many completion methods used to control cresting, among which variable density perforation is an effective one. It is difficult to evaluate well productivity and to analyze inflow profiles of horizontal wells with quantities of unevenly distributed perforations, which are characterized by different parameters. In this paper, fluid flow in each wellbore perforation, as well as the reservoir, was analyzed. A comprehensive model, coupling the fluid flow in the reservoir and the wellbore pressure drawdown, was developed based on potential functions and solved using the numerical discrete method. Then, a bottom water cresting model was established on the basis of the piston-like displacement principle. Finally, bottom water cresting parameters and factors influencing inflow profile were analyzed. A more systematic optimization method was proposed by introducing the concept of cumulative free-water production, which could maintain a balance (or then a balance is achieved) between stabilizing oil production and controlling bottom water cresting. Results show that the inflow profile is affected by
\end{abstract}

Dian-Fa Du

dudf@upc.edu.cn

Yan-Yan Wang

514375721@qq.com

1 School of Petroleum Engineering, China University of Petroleum, Qingdao 266580, Shandong, China

2 Sinopec Petroleum Exploration and Production Research Institute, Sinopec, Beijing 100083, China

3 Shengli Production Plant, Shengli Oilfield Branch Company, Sinopec, Dongying 257051, Shandong, China

Edited by Yan-Hua Sun the perforation distribution. Wells with denser perforation density at the toe end and thinner density at the heel end may obtain low production, but the water breakthrough time is delayed. Taking cumulative free-water production as a parameter to evaluate perforation strategies is advisable in bottom water reservoirs.

Keywords Bottom water reservoirs - Variable density perforation completion - Inflow profile $\cdot$ Cresting model · Cumulative free-water production

\section{Introduction}

Bottom water reservoirs are widely distributed on earth and hold a large proportion of oil reserves (Islam 1993). Taking China for example, there exist a large number of bottom water reservoirs, most of which are developed using horizontal wells. Compared with vertical wells, the producing sections of horizontal wells have direct contact with oil reservoirs, which not only reduces the producing pressure drawdown, but also ensures bottom water flowing into the wellbore more smoothly in a form of "pushing upward" (Besson and Aquitaine 1990; Dou et al. 1999; Permadi et al. 1996; Zhao et al. 2006). Owing to these advantages, it can effectively control bottom water cresting. The need of economic and effective development of bottom water reservoirs leads to the appearance of many types of completion methods, such as barefoot well completion, slotted screen well completion and perforation completion (Ouyang and Huang 2005). Recently, partial completion, variable density perforation completion and other new completion methods have been put forward to further control bottom water cresting (Goode and Wilkinson 1991; Sognesand et al. 1994). By accurately finding out the water 
production interval of horizontal wells, adopting plugging strategies or properly adjusting the bottom water inflow profile, these techniques can effectively prolong the life of production wells. And among all these techniques, perforation completion, including variable density perforation and selectively perforated completion, plays a critical role in alleviating water cresting (Pang et al. 2012).

Previously, scholars put more emphasis on the productivity evaluation of horizontal wells (Dikken 1990; Novy 1995; Penmatcha et al. 1998) and bottom water cresting (Permadi et al. 1995; Wibowo et al. 2004; Chaperon 1986). The published papers mostly focused on horizontal wells with open-hole completion. There is little research into horizontal wells with variable density perforation completion, and the ones that exist turned out to be very problematic: (1) The method for open-hole completion horizontal wells was used ignoring the fluid flow in perforation tunnels in these studies (Landman and Goldthorpe 1991; Yuan et al. 1996; Zhou et al. 2002). Then, a model describing the damage zone must be introduced to characterize the influence of perforation holes (Umnuayponwiwat and Ozkan 2000; Muskat and Wycokoff 2013). Some scholars utilized the numerical simulation method to discuss the impact of selective perforation on the productivity of horizontal wells and built a single-phase flow variable density perforation model for horizontal wells by two filtration zones ( $\mathrm{Li}$ et al. 2010). Since the seepage resistance needs to be considered more precisely, especially in the middle and later periods of the oilfield development, the existing results are somewhat inaccurate.

(2) Conventional simplified models cannot analyze formation pressure thoroughly and predict bottom water cresting. Furthermore, a non-uniformly distributed bottom water inflow profile along the wellbore was obtained without considering the wellbore pressure drop (Guo et al. 1992). (3) In order to optimize completion parameters for horizontal wells, oil production is usually viewed as the only objective function. It is reasonable for horizontal wells in conventional reservoirs. However, it is not accurate for horizontal wells located in bottom water reservoirs because of ignoring bottom water cresting, which decreases the effective production period of wells (Luo et al. 2015).

In this paper, based on the precise consideration of the fluid flow in each perforation, the flow behavior in perforations, wellbores, as well as reservoirs, was analyzed. Coupling the fluid flow in reservoirs and wellbore pressure drop, a comprehensive model, which can be used to evaluate productivity of horizontal wells, was developed based on potential functions and solved using the numerical discrete method. Then, a model describing bottom water cresting was established on the basis of the piston-like displacement principle. Finally, both the bottom water cresting behavior and the factors influencing inflow profile were analyzed using the developed model, and a more systematic optimization method was proposed by introducing the concept of the cumulative free-water production, which could realize a balance between stabilizing oil production and controlling bottom water coning.

\section{Productivity analysis for horizontal wells with variable density perforation completion}

For horizontal wells with perforation completed in bottom water reservoirs, formation fluids firstly flow into perforation holes before converging in the horizontal wellbore. Under this circumstance, the effect of perforation holes is similar to that of short producing branches in inclined horizontal wells (Holmes et al. 1998). The real producing part for horizontal wells should be quantities of perforation holes. Therefore, the perforation holes can be regarded as "source-sink" term, and this kind of problem can be solved with a source function.

\subsection{Analysis of fluid flow near wellbore regions}

A model was built to describe the flow of formation fluid near horizontal wellbores, and the assumptions for this model are as follows:

(1) The formation is homogeneous with a uniform thickness;

(2) The horizontal permeability meets the following basic relationship: $K_{x}=K_{y}=K_{\mathrm{h}}$, and the vertical permeability is $K_{z}=K_{\mathrm{v}}$. The target reservoir is infinite in the horizontal plane;

(3) The single-phase fluid flowing in the reservoir is incompressible and the fluid flow obeys Darcy's law;

(4) The wellbore is horizontal, in which the perforations are unevenly distributed;

(5) The perforating direction is perpendicular to the wellbore, and the lengths as well as radius of all the perforation tunnels are the same.

Acoordinate system is established as shown in Fig. 1, in which the heel end of the wellbore is $M_{0}\left(x_{0}, y_{0}, z_{0}\right)$. The horizontal part of the wellbore (total length $L, \mathrm{~m}$ ) is divided into $N$ segments. Therefore, the length of each segment is $L / N$.

Different segments have different characteristic parameters: the perforation density, $n_{\mathrm{p}}(i)$; the perforation depth, $l_{\mathrm{p}}$; bore diameter, $D_{\mathrm{p}}$; phase angle $\omega$; and the initial perforation angle $\omega_{0}$. The heel end is selected as the origin of this coordinate, and the $x$ direction is parallel with the wellbore. The coordinates of any point $(x, y, z)$ in the $j$ th perforation tunnel in the $i$ th segment are as follows: 


$$
\left\{\begin{array}{l}
x_{\mathrm{p}}(i, j, t)=x_{0}+\frac{L}{N}\left(\sum_{k=1}^{i-1} \sin \theta_{k} \cos \alpha_{k}+\frac{j}{n_{\mathrm{p}}(i)} \sin \theta_{i} \cos \alpha_{i}+t \cdot l_{\mathrm{p}} \sin \gamma_{i j} \cos \chi_{i j}\right) \\
y_{\mathrm{p}}(i, j, t)=y_{0}+\frac{L}{N}\left(\sum_{k=1}^{i-1} \sin \theta_{k} \sin \alpha_{k}+\frac{j}{n_{\mathrm{p}}(i)} \sin \theta_{i} \sin \alpha_{i}+t \cdot l_{\mathrm{p}} \sin \gamma_{i j} \sin \chi_{i j}\right) \\
z_{\mathrm{p}}(i, j, t)=z_{0}+\frac{L}{N} \sum_{k=1}^{i-1} \cos \theta_{k}+\frac{j}{n_{\mathrm{p}}(i)} \cos \theta_{i}+t \cdot l_{\mathrm{p}} \cos \gamma_{i j}
\end{array} \quad(0 \leq t \leq 1)\right.
$$

where $\theta_{k}$ is the angle between the $k$ th segment and the vertical direction, $k=1,2, \ldots, i-1 ; \alpha_{k}$ is the angle between the $x$-axis and the projection of the $k$ th segment in the horizontal plane, $k=1,2, \ldots, i-1 . \theta_{i}$ is the angle between the $i$ th segment and the vertical direction; $\alpha_{i}$ is the angle between the $x$-axis and the projection of the $i$ th segment in the horizontal plane; $\gamma_{i j}$ is the angle between the $j$ th perforation in the $i$ th producing part of the horizontal well and the $z$-axis; $\chi_{i j}$ is the angle between the $x$ axis and the projection in the $x y$ plane of the $j$ th perforation in the $i$ th segment of the horizontal well; in this paper, when all the perforation is perpendicular to the horizontal wellbore, then $\chi_{i, j}=\pi / 2$.

According to the classical theory of flow in porous media (Cheng 2011), the fluid flow at any point in an infinite reservoir obeys the Laplace equation. So we have:

$\frac{\partial^{2} p}{\partial x^{2}}+\frac{\partial^{2} p}{\partial y^{2}}+\frac{K_{\mathrm{v}}}{K_{\mathrm{h}}} \frac{\partial^{2} p}{\partial z^{2}}=0$

where $p$ is the pressure, MPa; $K_{\mathrm{v}}$ is the vertical permeability, $\mu \mathrm{m}^{2}$; and $K_{\mathrm{h}}$ is the horizontal permeability, $\mu \mathrm{m}^{2}$.

Substituting linear transformation $z^{\prime}=\beta z$, where $\beta=\sqrt{K_{\mathrm{h}} / K_{\mathrm{v}}}$, into Eq. (2) gives:
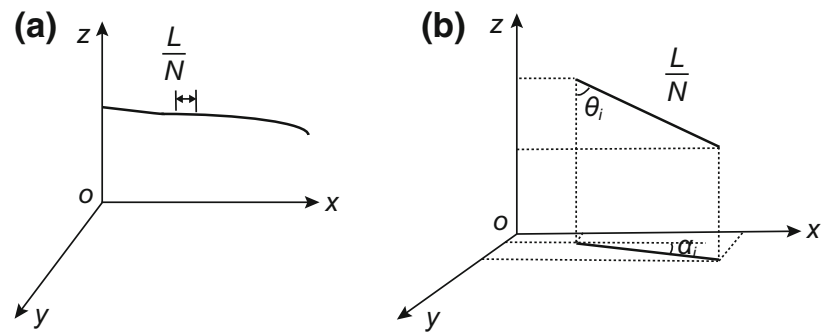

(c)

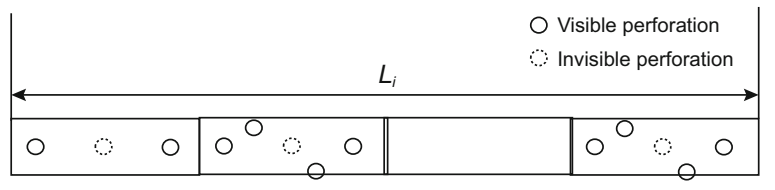

Fig. 1 Schematic diagram near the horizontal wellbore in a bottom water reservoir $\frac{\partial^{2} \Phi}{\partial x^{2}}+\frac{\partial^{2} \Phi}{\partial y^{2}}+\frac{\partial^{2} \Phi}{\partial z^{\prime 2}}=0$

where $\Phi=\sqrt{K_{\mathrm{h}} K_{\mathrm{v}}} / \mu_{\mathrm{o}} p, \mathrm{~m}^{2} / \mathrm{s} ; \mu_{\mathrm{o}}$ is the oil viscosity, $\mathrm{mPa}$; ; and also the corresponding parameters of the perforation become:

$$
\begin{aligned}
& l_{\mathrm{p}}^{\prime}=l_{\mathrm{p}} \sqrt{\beta^{2} \cos \gamma_{i j}^{2}+\frac{1}{\beta^{2}} \sin \gamma_{i j}^{2}} ; \\
& \sin \gamma_{i j}^{\prime}=\frac{\beta \sin \gamma_{i j}}{\sqrt{\beta^{2} \cos \gamma_{i j}^{2}+\frac{1}{\beta^{2}} \sin \gamma_{i j}^{2}}} ; \\
& \cos \gamma_{i j}^{\prime}=\frac{\cos \gamma_{i j}}{\beta \sqrt{\beta^{2} \cos \gamma_{i j}^{2}+\frac{1}{\beta^{2}} \sin \gamma_{i j}^{2}}} .
\end{aligned}
$$

In order to simplify the solution procedure, one assumption that the flow rates of all perforations in each segment are equal, is proposed (Wang et al. 2006):

$q_{\mathrm{p}}=\frac{q_{\mathrm{ra}}(i)}{\Delta x n_{\mathrm{p}}(i)}$

where $q_{\mathrm{p}}$ is the flow rate of each perforation at the $i$ th segment, $\mathrm{m}^{3} / \mathrm{s} ; q_{\mathrm{ra}}(i)$ is the flow rate of the $i$ th segment, $\mathrm{m}^{3} /$ $\mathrm{s} ; \Delta x$ is the length of the $i$ th segment, which is equal to $L / N$, $\mathrm{m}$; and $n_{\mathrm{p}}(i)$ is the perforation density of the $i$ th segment, holes $/ \mathrm{cm}$.

Compared with the length of the horizontal wellbore, the perforation is rather short. Therefore, it can be regarded as an infinitesimal line source. After integrating the point sink solution over the perforation direction, the pressure response of any perforation hole in the formation is obtained. For example, the potential at point $M\left(x, y, z^{\prime}\right)$ caused by the $j$ th perforation in the $i$ th segment can be described as:

$$
\begin{aligned}
& \Phi_{i j}\left(x, y, z^{\prime}\right)=\int_{0}^{l_{\mathrm{p}}}-\frac{q_{\mathrm{r}}(i, j)}{4 \pi l_{\mathrm{p}} r} \mathrm{~d} s+C_{i j} \\
& =\int_{0}^{l_{\mathrm{p}}}-\frac{N q_{\mathrm{ra}}(i)}{4 \pi l_{\mathrm{p}} L n_{\mathrm{p}}(i) \sqrt{\left(x_{\mathrm{p}}-x\right)^{2}+\left(y_{\mathrm{p}}-y\right)^{2}+\left(z_{\mathrm{p}}^{\prime}-z^{\prime}\right)^{2}}} \mathrm{~d} s+C_{i j}
\end{aligned}
$$


The integration of Eq. (5) is as follows:

$\Phi_{i j}\left(x, y, z^{\prime}\right)=-\frac{N q_{\mathrm{ra}}(i)}{4 \pi l_{\mathrm{p}} L n_{\mathrm{p}}(i)} \ln \frac{r_{1 i j}+r_{2 i j}+l_{\mathrm{p}}^{\prime}}{r_{1 i j}+r_{2 i j}-l_{\mathrm{p}}^{\prime}}+C_{i j}$

where $q_{\mathrm{r}}(i, j)$ is the flow rate of the $j$ th perforation tunnel in the $i$ th segment, $\mathrm{m}^{3} / \mathrm{s} ; r$ is the distance between the source point $M_{\mathrm{p}}\left(x, y, z^{\prime}\right)$ and the target point $M\left(x, y, z^{\prime}\right) ; C_{i j}$ is an integration constant; $r_{1 i j}$ is the distance between the heel end and the target point; $r_{2 i j}$ is the distance between the toe end and the target point, and they observe the following expressions, respectively:

$r_{1 i j}=\sqrt{\left[x_{\mathrm{p}}(i, j, 0)-x\right]^{2}+\left[y_{\mathrm{p}}(i, j, 0)-y\right]^{2}+\left[z_{\mathrm{p}}^{\prime}(i, j, 0)-z^{\prime}\right]^{2}}$

$r_{2 i j}=\sqrt{\left[x_{\mathrm{p}}(i, j, 1)-x\right]^{2}+\left[y_{\mathrm{p}}(i, j, 1)-y\right]^{2}+\left[z_{\mathrm{p}}^{\prime}(i, j, 1)-z^{\prime}\right]^{2}}$

where $x_{\mathrm{p}}(i, j, 0), y_{\mathrm{p}}(i, j, 0), z_{\mathrm{p}}(i, j, 0)$ and $x_{\mathrm{p}}(i, j, 1), y_{\mathrm{p}}(i, j, 1)$, $z_{\mathrm{p}}(i, j, 1)$ are the coordinates of the left and right ends of the $j$ th perforation in the $i$ th producing part.

Based on the mirror image reflection and superposition principle, the potential of the $j$ th perforation tunnel for the $i$ th production segment at point $M_{\mathrm{p}}\left(x, y, z^{\prime}\right)$ is obtained:

$$
\begin{aligned}
\Phi\left(x, y, z^{\prime}\right)= & -\frac{N q_{\mathrm{ra}}(i)}{4 \pi l_{\mathrm{p}} L n_{\mathrm{p}}(i)} \sum_{n=-\infty}^{+\infty}\left\{\xi _ { i j } \left(2 h^{\prime}+4 n h^{\prime}-z_{\mathrm{p} i j}^{\prime}(i, j, 0)\right.\right. \\
& \left.2 h^{\prime}+4 n h^{\prime}-z_{\mathrm{p} i j}^{\prime}(i, j, 1), x, y, z^{\prime}\right) \\
& +\xi_{i j}\left(4 n h^{\prime}+z_{\mathrm{p} i j}^{\prime}(i, j, 0), 4 n h^{\prime}+z_{\mathrm{p} i j}^{\prime}(i, j, 1), x, y, z^{\prime}\right) \\
& -\xi_{i j}\left(-2 h^{\prime}+4 n h^{\prime}+z_{\mathrm{p} i j}^{\prime}(i, j, 0),-2 h^{\prime}\right. \\
& \left.+4 n h^{\prime}+z_{\mathrm{p} i j}^{\prime}(i, j, 1), x, y, z^{\prime}\right) \\
& -\xi_{i j}\left(4 n h^{\prime}-z_{\mathrm{p} i j}^{\prime}(i, j, 0), 4 n h^{\prime}\right. \\
& \left.\left.-z_{\mathrm{p} i j}^{\prime}(i, j, 1), x, y, z^{\prime}\right)+C_{i}^{\prime}\right\}
\end{aligned}
$$

with

$$
\begin{aligned}
& \xi_{i j}\left(\varepsilon_{0}, \varepsilon_{1}, x, y, z^{\prime}\right)=\ln \frac{r_{1 i j}+r_{2 i j}+l_{\mathrm{p}}^{\prime}}{r_{1 i}+r_{2 i}-l_{\mathrm{p}}^{\prime}} \\
& r_{1 i}=\sqrt{[x(i, j, 0)-x]^{2}+[y(i, j, 0)-y]^{2}+\left[\varepsilon_{0}-z^{\prime}\right]^{2}} \\
& r_{2 i}=\sqrt{[x(i, j, 1)-x]^{2}+[y(i, j, 1)-y]^{2}+\left[\varepsilon_{1}-z^{\prime}\right]^{2}}
\end{aligned}
$$

According to the superposition principle, the potential at any point of the infinite formation created by all the perforation tunnels of the horizontal well is:

$\Phi_{i j}\left(x, y, z^{\prime}\right)=-\frac{N}{4 \pi l_{\mathrm{p}} L} \sum_{i=1}^{N} \frac{q_{\mathrm{ra}}(i)}{n_{\mathrm{p}}(i)} \sum_{j=1}^{\frac{L}{N} n_{\mathrm{p}}(i)} \ln \phi_{i j}+C$ with

$$
\begin{aligned}
\phi_{i j}= & \sum_{n=-\infty}^{+\infty}\left\{\xi _ { i j } \left(2 h^{\prime}+4 n h^{\prime}-z_{\mathrm{p} i j}^{\prime}(i, j, 0), 2 h^{\prime}+4 n h^{\prime}\right.\right. \\
- & \left.z_{\mathrm{p} i j}^{\prime}(i, j, 1), x, y, z^{\prime}\right)+\xi_{i j}\left(4 n h^{\prime}+z_{\mathrm{p} i j}^{\prime}(i, j, 0), 4 n h^{\prime}\right. \\
& \left.\quad+z_{\mathrm{p} i j}^{\prime}(i, j, 1), x, y, z^{\prime}\right) \\
- & \xi_{i j}\left(-2 h^{\prime}+4 n h^{\prime}+z_{\mathrm{p} i j}^{\prime}(i, j, 0),-2 h^{\prime}\right. \\
& \left.\quad+4 n h^{\prime}+z_{\mathrm{p} i j}^{\prime}(i, j, 1), x, y, z^{\prime}\right) \\
& \left.-\xi_{i j}\left(4 n h^{\prime}-z_{\mathrm{p} i j}^{\prime}(i, j, 0), 4 n h^{\prime}-z_{\mathrm{p} i j}^{\prime}(i, j, 1), x, y, z^{\prime}\right)+\frac{2 l_{\mathrm{p}}}{n h^{\prime}}\right\} C_{i}^{\prime}
\end{aligned}
$$

The boundary pressure at the oil-water interface is assumed to be constant. Therefore, the potential at any point of the formation may be expressed as:

$\Phi_{i j}\left(x, y, z^{\prime}\right)=\Phi_{\mathrm{e}}-\frac{N}{4 \pi l_{\mathrm{p}} L} \sum_{i=1}^{N} \frac{q_{\mathrm{ra}}(i)}{n_{\mathrm{p}}(i)} \sum_{j=1}^{\frac{L}{N} n_{\mathrm{p}}(i)} \ln \phi_{i j}$

Combining the definition of potential, the pressure at any point of the formation can be given as follows:

$p_{\mathrm{wf}, i j}\left(x, y, z^{\prime}\right)=p_{\mathrm{e}}-\frac{N \mu_{\mathrm{o}}}{4 \pi l_{\mathrm{p}} L \sqrt{K_{\mathrm{h}} K_{\mathrm{v}}}} \sum_{i=1}^{N} \frac{q_{\mathrm{ra}}(i)}{n_{\mathrm{p}}(i)} \sum_{j=1}^{\frac{L}{N} n_{\mathrm{p}}(i)} \ln \phi_{i j}$

where $p_{\mathrm{e}}$ is the boundary pressure, MPa.

For perforated completion, the perforation tunnels directly contact the formation. Therefore, the flow potential of some point, which is just located in the perforation, can be obtained using Eq. (15). In this case, there are two points involved: the target point and the source point (perforation point). To get rid of singularity phenomenon, the central hole in the wall is chosen as the jth perforation's target point when calculating the distance between two perforation points.

Only calculating the pressure of one central point for the segment and regarding it as the pressure of the whole segment will result in deviation when analyzing the segment's pressure of a horizontal wellbore. In this paper, taking the average over all the perforations' pressure in the same segment and using the average value as the representative pressure of that segment, the pressure of the $i$ th segment is as follows:

$p_{\mathrm{wf}}(i)=\frac{1}{\Delta x n_{\mathrm{p}}(i)} \sum_{j=1}^{\Delta x n_{\mathrm{p}}(i)} p_{\mathrm{wf}}(i, j)$

where $p_{\mathrm{wf}}(i)$ is the flow pressure for all the perorations in the $i$ th segment, MPa. 
There are $2 N$ variables required to be calculated by analyzing pressure distribution along the wellbore: $p_{\mathrm{wf}}(i)$ and $q_{\mathrm{ra}}(i),(i=1,2, \ldots, N)$. However, it only contains $N$ equations in the flow model [Eq. (15)]. Therefore, one more model is needed to describe pressure drop along the wellbore ( $\mathrm{Li}$ et al. 1996, 2006).

\subsection{Wellbore pressure drop model}

For perforated horizontal wells, the main idea to develop a wellbore pressure drop model is to divide the horizontal wellbore into several segments, and each segment is subdivided into several smaller parts that only include one perforation (Su and Gudmundsson 1994).

According to the analysis of the pressure drop in a wellbore, the total pressure loss can be written as:

$\mathrm{d} p_{\mathrm{wf}}(i)=\mathrm{d} p_{\text {fric }}(i)+\mathrm{d} p_{\text {acc }}(i)+\mathrm{d} p_{\text {mix }}(i)+\mathrm{d} p_{\mathrm{G}}(i)$

where $\mathrm{d} p_{\text {fric }}(i)$ is the friction loss of the $i$ th segment, MPa; $\mathrm{d} p_{\text {acc }}(i)$ is the acceleration loss of the $i$ th segment, MPa; $\mathrm{d} p_{\text {mix }}(i)$ is the mixing loss of the $i$ th segment, MPa; and $\mathrm{d} p_{\mathrm{G}}(i)$ is the gravity loss of the $i$ th segment, MPa.

It should be noted that, in the previous section, a mechanical field described by the flow model is established based on the potential function. Therefore, when the potential function is used to deal with flow problems, the pressure loss caused by viscous force has been considered. As we all know, the mathematical expression of fluid potential is $K p / \mu$, where $K$ is the formation permeability, $p$ represents pressure, while $\mu$ means the fluid viscosity, and it is used to describe the viscous force, which will lead to pressure loss along the perforation. So it means that the viscous force has been taken into consideration in the first model. In other words, when building wellbore pressure here, only four kinds of pressure loss should be calculated.

The calculation method of frictional loss and acceleration loss between two perforation tunnels is expressed, respectively.

$$
\begin{aligned}
\Delta p_{\text {fric }} & =1.34 \times 10^{-13} f_{\text {fric }}(i, j) \frac{\Delta l}{D} \frac{\rho \bar{v}_{\mathrm{s}}^{2}(i, j)}{2} \\
& =1.0862 \times 10^{-13} f_{\text {fric }}(i, j) \frac{\rho q_{\mathrm{L}}^{2}(i, j)}{D^{5} n_{\mathrm{p}}(i)}
\end{aligned}
$$

$$
\begin{aligned}
\Delta p_{\text {acc }}(i, j) & =\rho\left[\bar{v}_{\mathrm{s}}^{2}(i, j)-\bar{v}_{\mathrm{s}}^{2}(i, j+1)\right] \\
& =3.5215 \times 10^{-13} \frac{\rho}{D^{5}}\left[q_{\mathrm{L}}^{2}(i, j)-q_{\mathrm{L}}^{2}(i, j+1)\right]
\end{aligned}
$$

where $\rho$ is the liquid density, $\mathrm{kg} / \mathrm{m}^{3} ; D$ is the wellbore diameter, $\mathrm{m} ; q_{\mathrm{L}}(i, j)$ is the flow rate along the wellbore, $\mathrm{m}^{3} /$ $\mathrm{d} ; \bar{v}_{\mathrm{s}}(i, j)$ is the average velocity of the $j$ th perforation in the $i$ th segment, $\mathrm{m} / \mathrm{s}$; and $f_{\text {fric }}(i, j)$ is the friction coefficient of the $j$ th perforation in the $i$ th segment.

In Eq. (19), one parameter, called the friction coefficient, is introduced. The calculation of the friction coefficient is dependent on the Reynolds number. If the Reynolds number is less than or equal to 2000 , the flow is laminar; otherwise, it is turbulent flow. And the expression for the Reynolds number is as follows:

$R e=7.3682844 \times 10^{-3} \frac{Q \rho}{r \mu}$

where $R e$ is the Reynolds number; $Q$ is the axial flow rate along the wellbore, $\mathrm{m}^{3} / \mathrm{d} ; \mu$ is the viscosity of the flowing fluid, $\mathrm{mPa} \mathrm{s}$; and $r$ is the wellbore radius, $\mathrm{m}$.

In addition, we also introduced a criterion when calculating the mixing loss between two perforation holes. The specific calculation method for frictional loss and mixing losses is listed in Table 1. In Table $1, q_{\mathrm{c}}$ is the critical rate, $\mathrm{m}^{3} / \mathrm{d} ; \varepsilon$ is the surface roughness, $\mathrm{mm}$.

When calculating the mixing loss, one parameter, $\Delta p_{\text {per }}$, is introduced. It is the frictional loss showing up after perforating and can be figured out using Eq. (19).

The friction loss, acceleration loss and the mixing loss of the $i$ th segment are listed below:

$$
\begin{aligned}
\mathrm{d} p_{\text {fric }}(i) & =1.0862 \times 10^{-13} \frac{\rho}{D^{5}} \sum_{j=1}^{\Delta x n_{\mathrm{p}}(i)} f_{\text {fric }}(i, j) \frac{q_{\mathrm{L}}^{2}(i, j)}{n_{\mathrm{p}}(i)} \\
\mathrm{d} p_{\text {acc }}(i) & =\sum_{j=1}^{\Delta x n_{\mathrm{p}}(i)} \Delta p_{\text {acc }}(i, j) \\
& =3.5215 \times 10^{-13} \frac{\rho}{D^{5}} \sum_{j=1}^{\Delta x n_{\mathrm{p}}(i)}\left[q_{\mathrm{L}}^{2}(i, j)-q_{\mathrm{L}}^{2}(i, j+1)\right]
\end{aligned}
$$

$\mathrm{d} p_{\text {mix }}(i)=\sum_{j=1}^{n_{\mathrm{p}}(i)} \Delta p_{\text {mix }}(i, j)$

Table 1 Calculation method for friction coefficient and mixing loss between two perforation holes

\begin{tabular}{llll}
\hline Flow pattern & $\begin{array}{l}\text { Discriminant } \\
\text { standard }\end{array}$ & $\begin{array}{l}\text { Calculation of friction coefficient } f_{\text {fric }}(i, j)(\text { Cheng } \\
2011)\end{array}$ & $\begin{array}{l}\text { Calculation of mixing losses } \Delta p_{\text {mix }}(i, j)(\text { Cheng } \\
\text { 2011) }\end{array}$ \\
\hline Laminar flow & $q_{\mathrm{L}}(i, j)<q_{\mathrm{c}}$ & $\frac{64}{\operatorname{Re}(i, j)}$ & $\Delta p_{\mathrm{per}}(i, j)-0.31 \times 10^{7} \operatorname{Re}(i, j) \frac{q_{\mathrm{ra}}(i)}{\Delta x n_{\mathrm{p}}(i) q_{\mathrm{L}}(i, j)}$ \\
$\begin{array}{l}\text { Turbulent } \\
\text { flow }\end{array}$ & $q_{\mathrm{L}}(i, j)>q_{\mathrm{c}}$ & {$\left[-1.8 \lg \left[\frac{6.9}{\operatorname{Re}(i, j)}+\left(\frac{\varepsilon}{3.7 D}\right)^{1.11}\right]\right]^{2}$} & $0.76 \times 10^{3} \operatorname{Re}(i, j) \frac{q_{\mathrm{ra}}(i)}{\Delta x n_{\mathrm{p}}(i) q_{\mathrm{L}}(i, j)}$ \\
\hline
\end{tabular}


If the horizontal well is inclined, the gravity loss is non-ignorable, and the wellbore pressure drop model becomes:
In this paper, an iterative method is used to solve the above-mentioned model, and the iterative process is shown in Fig. 2.

$$
\Delta p_{\mathrm{wf}}(i, j)=\left\{\begin{array}{lc}
1.0862 \times 10^{-13} \frac{\rho}{D^{5}} \sum_{j=1}^{\Delta x n_{\mathrm{p}}(i)} f_{\text {fric }}(i, j) \frac{q_{\mathrm{L}}^{2}(i, j)}{n_{\mathrm{p}}(i)}+3.5215 \times 10^{-13} \frac{\rho}{D^{5}} \sum_{j=1}^{\Delta x n_{\mathrm{p}}(i)}\left[q_{\mathrm{L}}^{2}(i, j)-q_{\mathrm{L}}^{2}(i, j+1)\right] \\
+\rho g \Delta x \cos \theta_{i}+\sum_{j=1}^{n_{p}(i)} \Delta p_{\text {mix }}(i, j) & q_{\mathrm{ra}}(i) \neq 0 \\
1.0862 \times 10^{-13} \frac{\rho}{D^{5}} \sum_{j=1}^{\Delta x n_{\mathrm{p}}(i)} f_{\text {fric }}(i, j) \frac{q_{\mathrm{L}}^{2}(i, j)}{n_{\mathrm{p}}(i)}+\rho g \Delta x \cos \theta_{i} & q_{\mathrm{ra}}(i)=0
\end{array}\right.
$$

\subsection{Coupling model}

When a horizontal well begins to produce reservoir fluids, the fluids in the perforations connect the wellbore and oil reservoir together. Therefore, perforation is considered as an infinitesimal linear sink, which directly contacts reservoir and wellbore. Meanwhile, pressure responses are generated in the whole reservoir. The generated pressure responses near the perforations are associated with oil inflow in the radial direction of the horizontal wellbore, which can be calculated by utilizing the reservoir flow model. Since the pressure in perforation holes is relevant to the wellbore pressure, a coupling relationship exists between the reservoir flow model and the wellbore pressure drop model.

According to the reservoir flow model, a model is developed to calculate steady-state productivity of the horizontal well with variable density perforation, in which the pressure drop along the horizontal wellbore is considered:

\section{Analysis of inflow profiles in bottom water reservoirs}

The bottom water rises fastest in the vertical plane of the horizontal wellbore (Cheng et al. 1994). In other words, the bottom water will firstly break through into the wellbore in this plane due to the highest pressure gradients in this profile. Therefore, a complicated 3-D problem can be turned into a 2-D problem in the $x z$ profile where the wellbore lies. The formation between the wellbore and the oil-water interface is discretized according to the division of the horizontal wellbore in the reservoir flow model. And the total number of grids in the vertical direction is $n_{z}$, which is shown in Fig. 3 .

The rise of bottom water is treated as a piston-like flooding process. That is to say, there is an obvious interface between the oil zone and the water zone. The oilwater contact moves upward to the horizontal wellbore in the vertical direction. Once it reaches any point of the wellbore, water breakthrough occurs there. According to the material balance theory (Xiong et al. 2013), we have:

$$
\left\{\begin{array}{l}
p_{\mathrm{wf}}(i)=p_{\mathrm{e}}-\frac{1}{l_{\mathrm{p}}} \frac{\mu}{4 \pi k \Delta x} \sum_{k=1}^{N} \frac{q_{\mathrm{ra}}(k)}{n_{\mathrm{p}}(k)} \sum_{j=1}^{\frac{L}{N} n_{\mathrm{p}}(k)} \phi_{k j} \quad k=1,2, \ldots, N ; \quad i=1,2, \ldots, \frac{L_{k}}{\Delta x} \\
p_{\mathrm{wf}}(i)=p_{\mathrm{wf}}(i-1)+0.5\left[\Delta p_{\mathrm{wf}}(i-1)+\Delta p_{\mathrm{wf}}(i)\right]
\end{array}\right.
$$

where $p_{\mathrm{wf}}(i)$ is the wellbore pressure in the $i$ th segment, $\mathrm{MPa} ; N$ is the number of divided segments along the wellbore; and $\phi_{k j}$ is a function corresponding to the horizontal wellbore as well as the oil-water interface.
$\left[S_{\mathrm{w}}(i, k+1)-S_{\mathrm{wc}}\right] \varphi \mathrm{d} x \mathrm{~d} y \mathrm{~d} z=v_{\mathrm{w}} \mathrm{d} x \mathrm{~d} y \mathrm{~d} t$

Based on Darcy's law, the water rise velocity is as follows: 


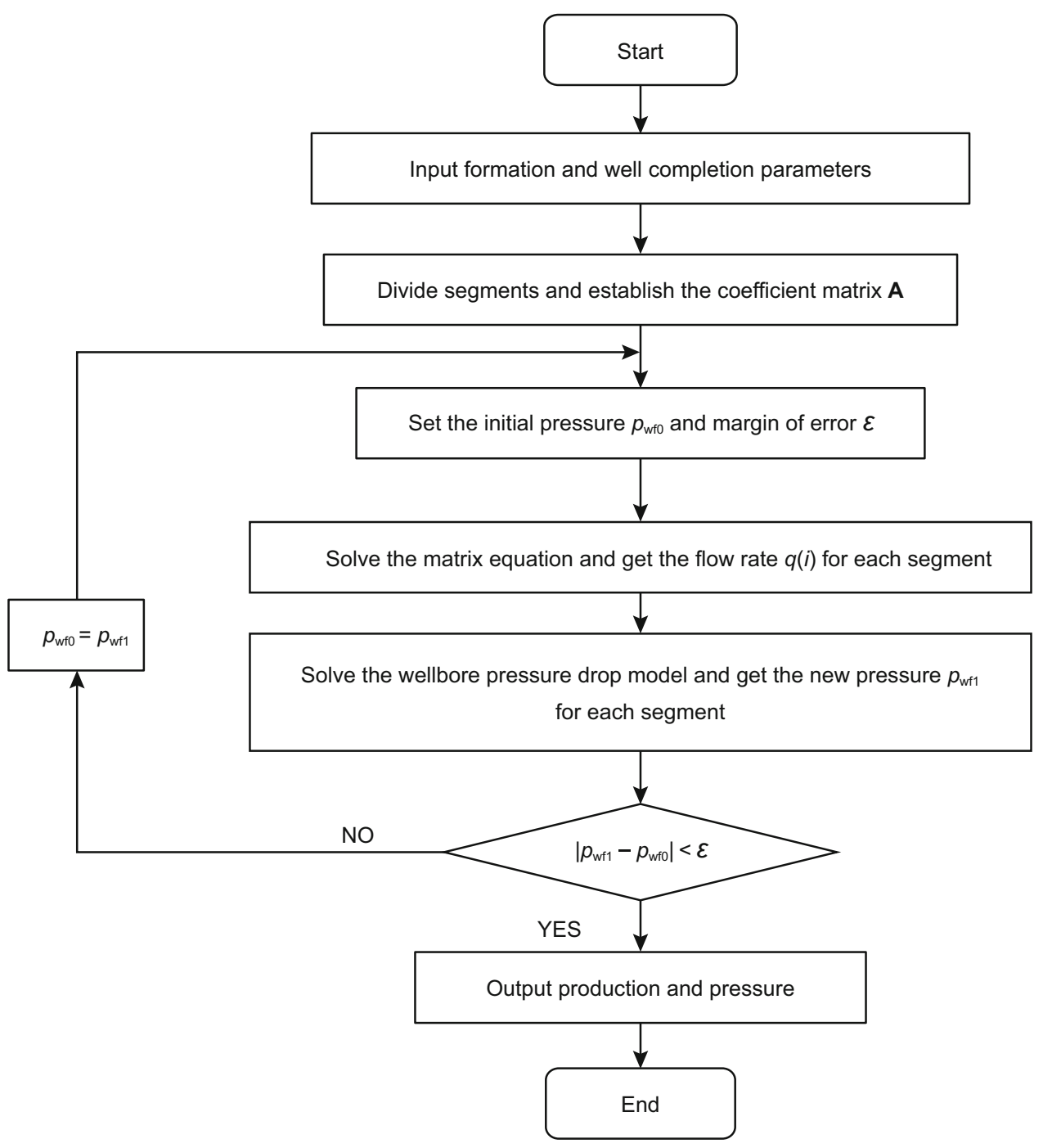

Fig. 2 Flowchart for solving the coupling model

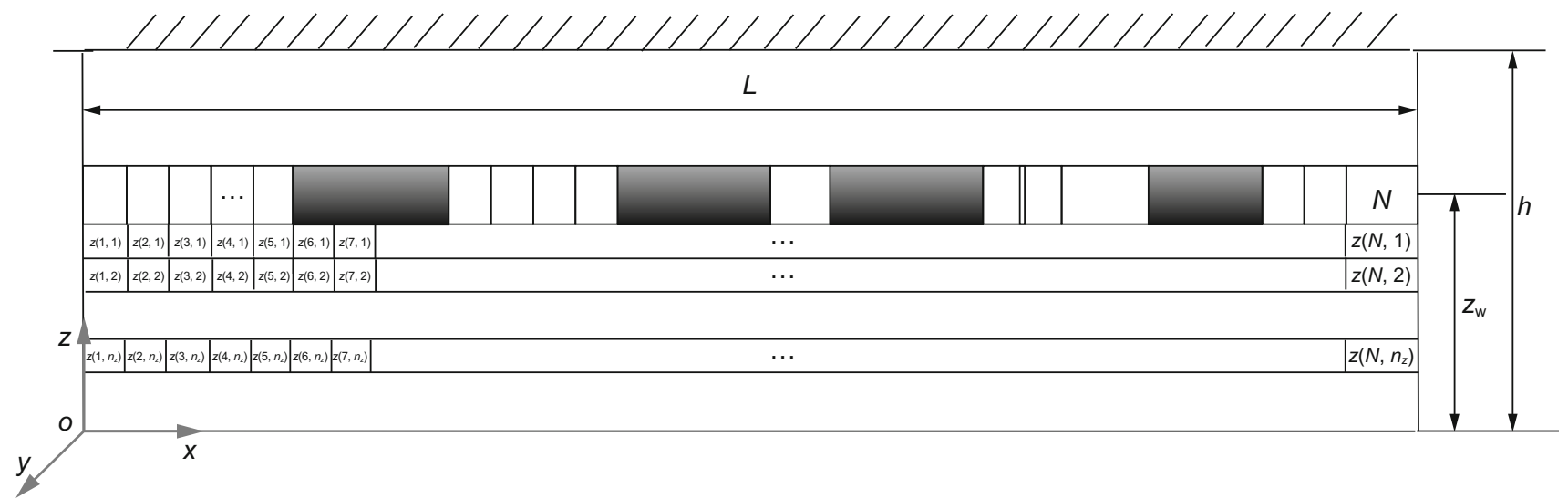

Fig. 3 Schematic diagram of the physical model for bottom water cresting 
$v_{\mathrm{w}}=\frac{K_{\mathrm{rw}} K_{\mathrm{v}}}{\mu_{\mathrm{w}}} \frac{\partial p(i, k)}{\partial z}$

where $S_{\mathrm{w}}(i, k+1)$ is the water saturation of the $(i, k+1)$ grid at time $t$ in the longitudinal profile; $S_{\mathrm{wc}}$ is the connate water saturation; $K_{\mathrm{rw}}$ is the relative permeability to water; and $\mu_{\mathrm{w}}$ is the water viscosity, $\mathrm{mPa}$ s.

According to the results of grid discretization, the vertical pressure gradients between any two contiguous grids are as follows:

$$
\left\{\begin{aligned}
\Delta p(i, k) & =p(i, k+1)-p(i, k) & & k=1,2, \ldots, n_{z}-1 \\
\Delta p(i, k) & =p_{\mathrm{wf}}(i)-p(i, k) & k & =n_{z}
\end{aligned}\right.
$$

Substituting Eqs. (28) into (27) gives the rise velocity of bottom water:

$v_{\mathrm{w}}(i, k)=\frac{K_{\mathrm{rw}} K_{\mathrm{v}}}{\mu_{\mathrm{w}}} \frac{\Delta p(i, k)}{\Delta z}$

According to the established mathematical model, the pressure at any grid between the oil-water contact surface and the horizontal wellbore can be written as:

$p_{\mathrm{wf}}(i, k)=p_{\mathrm{e}}-\frac{N \mu_{\mathrm{o}}}{4 \pi L \sqrt{K_{\mathrm{h}} K_{\mathrm{v}}}} \sum_{i=1}^{N} q(i, k) \phi_{i k}$

Combining with Eq. (26), the time required for the water rising from the $(k+1)$ th grid to the $k$ th grid is obtained:

$t(i, k)=\frac{\varphi \mu_{\mathrm{w}}}{K_{\mathrm{rw}} K_{v}} \frac{\left[S_{\mathrm{w}}(i, k)-S_{\mathrm{wc}}\right](\Delta z)^{2}}{\Delta p(i, k)}$

The breakthrough time at the $i$ th segment is:

$t_{\mathrm{a}}=\sum_{k=1}^{n_{z}} t(i, k)$

where $\varphi$ is the porosity; $n_{\mathrm{z}}$ is the number of meshes in the longitudinal direction between the wellbore and the oilwater interface.

\section{Case study}

Using the developed model, the well productivity and water breakthrough for a horizontal well in a bottom water drive reservoir were evaluated. Table 2 lists the bottom water drive reservoir properties and its drilling and completion parameters.

The steady-state productivity of the horizontal well with variable density perforation completion was evaluated, and also the bottom water inflow profile was calculated. A set of basic variable density perforation cases are designed and are shown in Fig. 4. For simplicity, the average perforation density of each case is 2 shots $/ \mathrm{m}$. In Case 1 , the perforation is uniformly distributed. In Cases 2 and 3, the perforation density at the heel end of the horizontal well is larger than that at the toe end of the horizontal well, while the perforation density is denser at the toe end than that at the heel end for Cases 4-6.

The simulation results for all the six cases are shown in Figs. 5, 6, 7, 8 and 9. Figure 5 shows the pressure distribution along the horizontal wellbore. In fact, there exists a pressure drop along the perforation hole. However, it has little relationship with our research object; thus, the relevant calculation was not carried out in this work. In order to better identify their characteristics, the pressure distribution curves of only three cases (Cases 1,2 and 5) are plotted together in Fig. 5. It can be seen that the pressure distribution curves are steep near the heel end of the horizontal wellbore, while relatively flat at the toe end. In addition, the greater the pressure drop is, the denser the perforations will be. Near the toe end, the pressure of Case 5 is higher than those of Case 1 and Case 2, indicating a denser perforation and a greater pressure drop in this location, while near the heel end, the difference of these three curves is smaller. Figure 6 shows the friction and acceleration losses (Case 1) along the wellbore, respectively. At any point of the horizontal wellbore, the friction loss is greater than the acceleration loss, and the former is nearly six times as much as the latter, which means the friction loss plays a leading role.

Figure 7 gives the flow rate distribution along the horizontal wellbore. For the horizontal well with uniformly distributed perforation, the flow rate at the toe end is lower than that at the heel end, due to the influence of the wellbore pressure drop. These six cases have the same number of perforations, and thus, the production is also similar, especially for Cases 1-3. For Case 3, although the difference of the flow rate between the heel end and the toe end is larger compared with the other five cases (Fig. 7), the production rate of the horizontal well is slightly larger (Fig. 8). Therefore, in order to maximize the production of the horizontal well, a perforation scheme with a larger perforation density at the toe end should be adopted. It should be noted that a larger perforation density at the toe end does not necessarily result in a higher production rate. The reason is that this kind of perforation scheme will lead to much lower flow rate at the toe end. In addition, Fig. 7 also shows that the flow rate distribution of Case 6 is more uniform compared with the other five cases. Due to the influence of the pressure drop along the wellbore and the reduced end effect, the flow rate distribution of Case 6 has a more uniform distribution of cresting height, which will delay the occurrence of bottom water breakthrough. Simulation results indicate that reducing the perforation density at the heel end is helpful for obtaining an evenly advancing 
Table 2 Parameters for the bottom water drive reservoir and its drilling and completion parameters

\begin{tabular}{llll}
\hline Parameter & Value & Parameter & Value \\
\hline Reservoir thickness, $\mathrm{m}$ & 28 & Bottom hole pressure, $\mathrm{MPa}$ & 20 \\
Pressure at the oil-water interface, $\mathrm{MPa}$ & 25 & Horizontal well length, $\mathrm{m}$ & 600 \\
Horizontal permeability, $\mu \mathrm{m}^{2}$ & 0.2 & Wellbore diameter, $\mathrm{cm}$ & 17.45 \\
Vertical permeability, $\mu \mathrm{m}^{2}$ & 0.05 & Water avoidance height, $\mathrm{m}$ & 21 \\
Oil density, $\mathrm{kg} / \mathrm{m}^{3}$ & 845 & Relative wellbore roughness & 0.0001 \\
Oil viscosity, $\mathrm{mPa} \mathrm{s}$ & 15.4 & Initial perforation phase angle & $\pi / 2$ \\
Perforation density, shots $/ \mathrm{m}$ & 2 & Angle between the wellbore and the $x$-axis & 0 \\
\hline
\end{tabular}

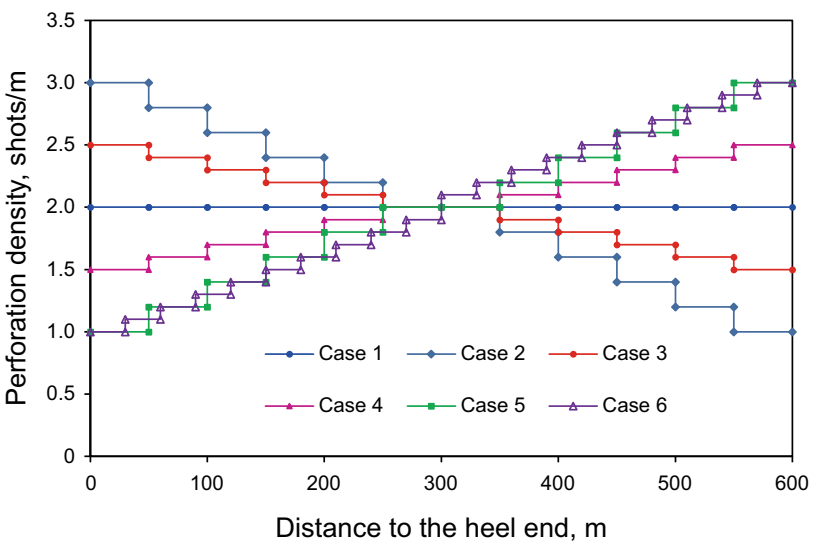

Fig. 4 Cases for variable density perforation

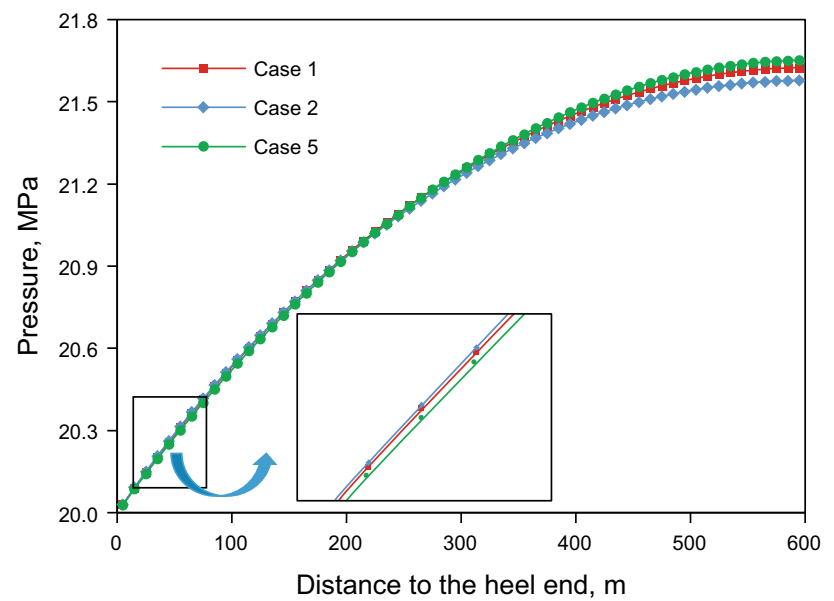

Fig. 5 Pressure distribution along the horizontal wellbore

water profile on the vertical plane of the horizontal wellbore.

The detailed distribution of bottom water breakthrough time along the wellbore is shown in Fig. 9. Compared with Case 1 (evenly distributed perforation), the redistribution of perforating density changes both the breakthrough location and breakthrough time simultaneously. It is obvious that the larger perforation density means a shorter breakthrough time. Meanwhile, the bottom water

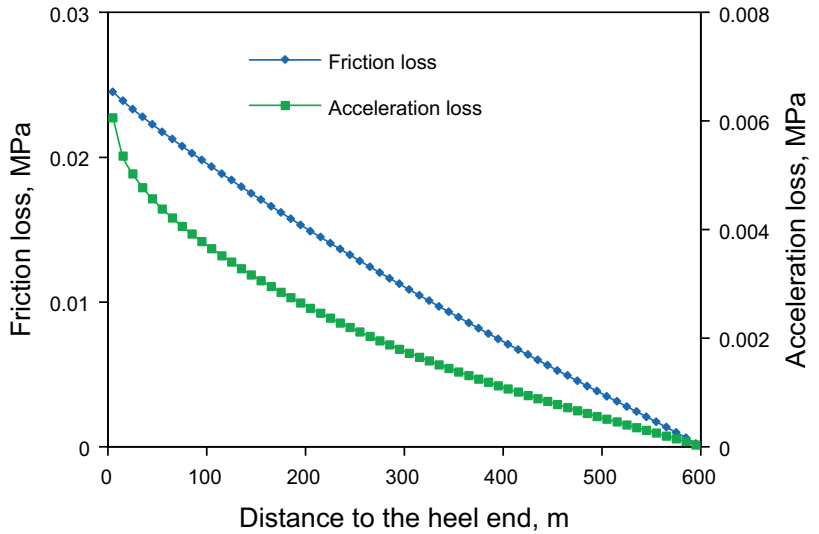

Fig. 6 Friction loss and acceleration loss along the horizontal wellbore for Case 1

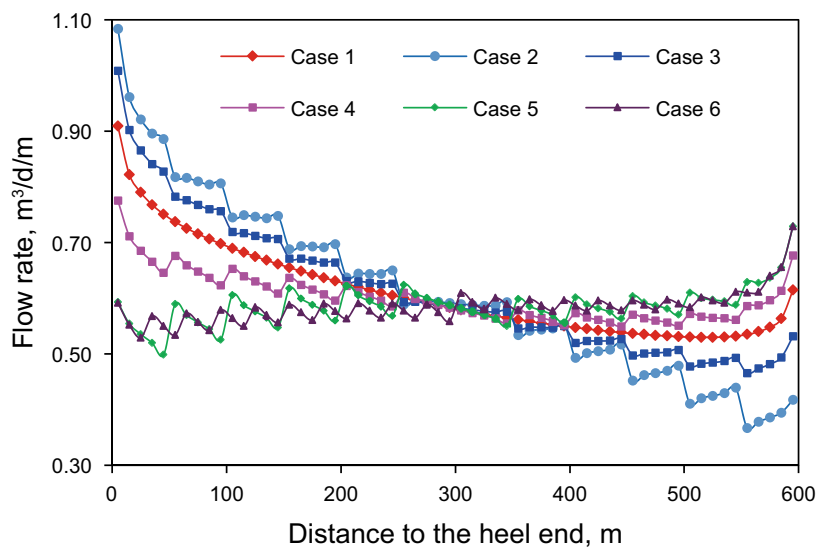

Fig. 7 Flow rate distribution along the horizontal wellbore for different cases

breakthrough location and time of the whole wellbore can be calculated by the developed model, as shown in Table 3 .

Figure 10 illustrates the distribution of the bottom water rising height along the wellbore for three different cases, which is in good agreement with the results in Fig. 9. The bottom water cresting height of Case 2 is shown in Fig. 11. It shows that the effect of the perforation density on bottom water cresting height becomes more serious with the increase of time. The deformation of the water ridge is 


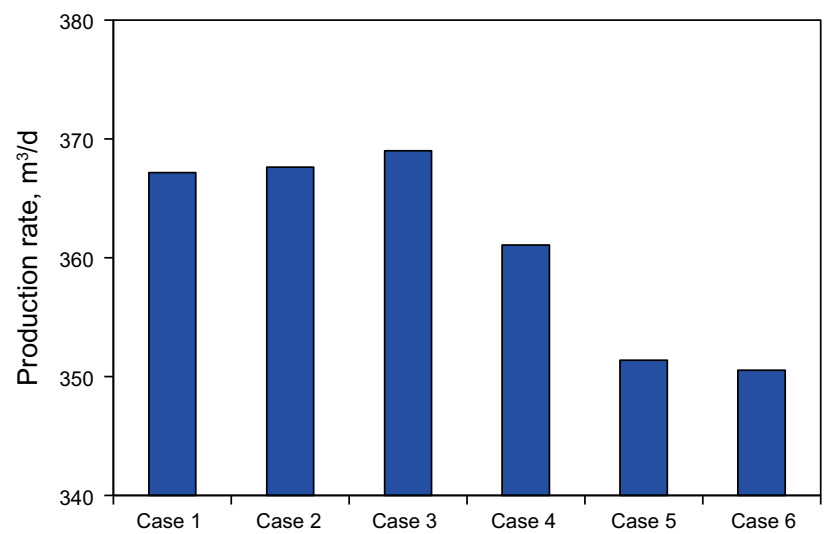

Fig. 8 Production rate of the horizontal well for different cases

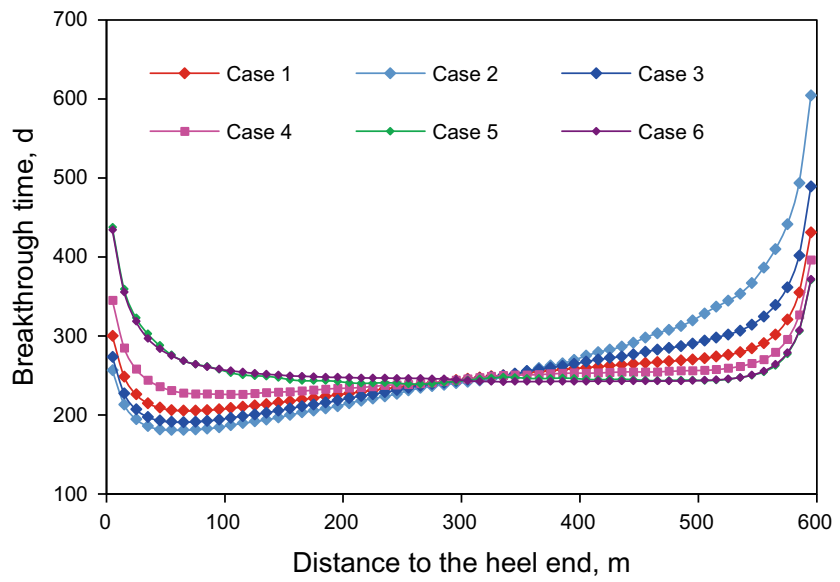

Fig. 9 Distribution of breakthrough time for different cases

obvious, which reflects on the degree of water crest asymmetry.

According to the above results, the perforation scheme with higher production (Cases 2 and 3) will advance the time of the bottom water breakthrough and thus have a negative effect on the development of bottom water reservoirs using horizontal wells. In other words, the

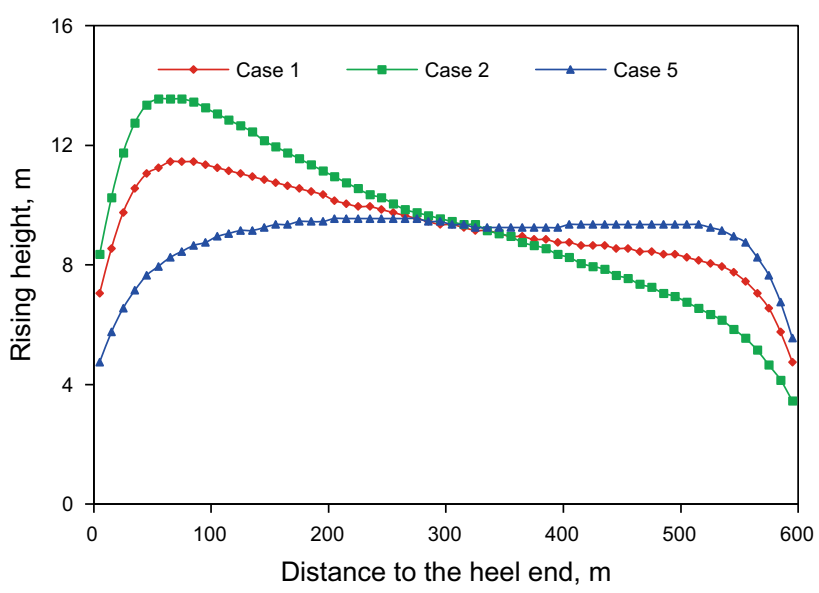

Fig. 10 Bottom water rising height for different cases (production time, 150 days)

horizontal well with a higher production rate will have a shorter water-free production period. So there exists a contradiction between increasing the well production and delaying the breakthrough time of bottom water. In order to comprehensively evaluate the effect of both controlling bottom water cresting and stabilizing oil production, a new parameter, called the cumulative free-water production, is defined as follows:

$Q_{\mathrm{o}}=q \times T_{\mathrm{o}}$

where $Q_{\mathrm{o}}$ is the cumulative oil production without water, $\mathrm{m}^{3} ; q$ is the rate when the horizontal well produces steadily, $\mathrm{m}^{3} / \mathrm{d}$; and $T_{\mathrm{o}}$ is the production time without water, $\mathrm{d}$.

Obviously, the cumulative oil production without water of the horizontal well could consider both the well production and effective production time.

According to the calculation results (Table 4), the $Q_{\mathrm{o}}$ of Cases 4 and 5 is higher than those of other Cases owing to the more uniform inflow profile. Therefore, for the horizontal well studied in this paper, the perforation scheme with denser perforation hole at the toe end and sparser perforation hole at the heel end is a more appropriate choice.

Table 3 Bottom water breakthrough location and time

\begin{tabular}{|c|c|c|c|c|}
\hline Case & $\begin{array}{l}\text { Distance between the } \\
\text { breakthrough point and the heel } \\
\text { end, } m\end{array}$ & $\begin{array}{l}\text { Breakthrough time at the first } \\
\text { breakthrough point, } d\end{array}$ & $\begin{array}{l}\text { Breakthrough time at the point } \\
100 \mathrm{~m} \text { away from the heel, } \mathrm{d}\end{array}$ & $\begin{array}{l}\text { Breakthrough time at the point } \\
500 \mathrm{~m} \text { away from the heel, } \mathrm{d}\end{array}$ \\
\hline 1 & 65 & 205.3 & 208.5 & 271.9 \\
\hline 2 & 55 & 180.8 & 187.1 & 328.5 \\
\hline 3 & 60 & 190.9 & 196.4 & 294.2 \\
\hline 4 & 105 & 226.0 & 226.2 & 256.5 \\
\hline 5 & 265 & 239.1 & 253.4 & 243.6 \\
\hline 6 & 335 & 242.1 & 256.0 & 284.9 \\
\hline
\end{tabular}




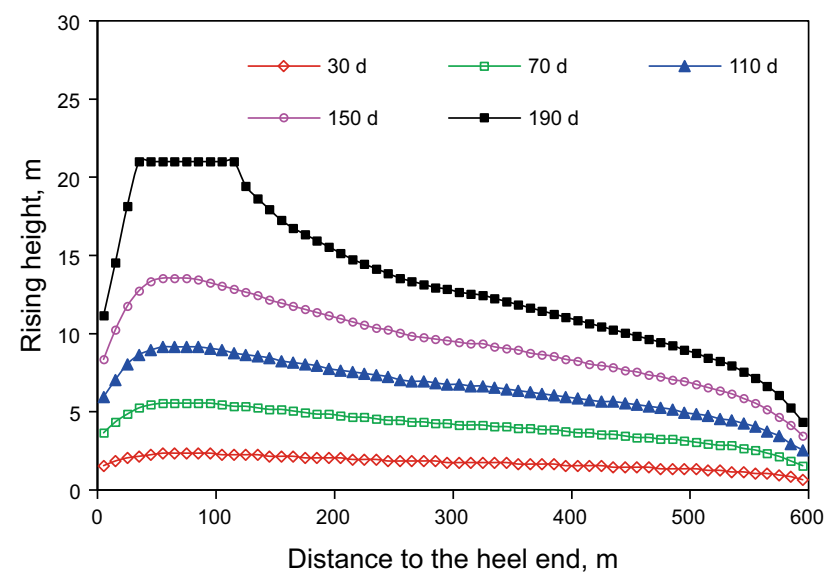

Fig. 11 Rising height of bottom water at different production times (Case 2)

Table 4 Parameters required for calculating $Q_{\mathrm{o}}$ of different cases

\begin{tabular}{lllll}
\hline Case & Breakthrough location, $\mathrm{m}$ & $T_{\mathrm{o}}, \mathrm{d}$ & $q, \mathrm{~m}^{3} / \mathrm{d}$ & $Q_{\mathrm{o}}, 10^{4} \mathrm{~m}^{3}$ \\
\hline 1 & 65 & 205.3 & 367.1 & 7.5 \\
2 & 55 & 180.8 & 367.6 & 6.6 \\
3 & 65 & 190.9 & 369.0 & 7.0 \\
4 & 105 & 226.0 & 361.0 & 8.2 \\
5 & 265 & 239.1 & 351.4 & 8.4 \\
\hline
\end{tabular}

\section{Conclusions}

In this paper, a model coupling fluid flow in reservoirs and pressure drop along the wellbore was developed to obtain the distribution of flow rate along the horizontal wellbore and to determine the horizontal well productivity. In this model, the fluid flow at each perforation hole was taken into account, and the perforation tunnels were treated as many infinitesimal sections. After that, a bottom water cresting model was developed based on the piston-like displacement principle, which could be used to calculate the bottom water breakthrough location, breakthrough time and the shape of water cresting at different times.

For a horizontal well with uniform density perforation completed in a bottom water reservoir, the pressure drop along the wellbore may significantly affect the water breakthrough mode. Specifically, the bottom water will firstly break through at the heel end of the wellbore. Neglecting the end effects, water breakthrough occurs in proper sequence from heel end to toe end. The bottom water breakthrough at a specific position will happen earlier if the perforation density is increased. When a horizontal well with denser perforation density at the toe end and sparser perforation density at the heel end, the lowest point of the distribution curve will move upward, which means the water breakthrough time is delayed. Under these circumstances, the horizontal well obtains a longer effective production period.

It is meaningful to take cumulative oil production without water as a parameter to evaluate the perforation strategies for horizontal wells. With this parameter, both the effects of productivity of the horizontal well and bottom water breakthrough time can be considered comprehensively. However, in order to simplify the calculation process, some assumptions have been introduced in this model, some of which are ideal ones and different from the actual reservoirs. Further work needs to be done in order to extend the application of this model.

Open Access This article is distributed under the terms of the Creative Commons Attribution 4.0 International License (http://crea tivecommons.org/licenses/by/4.0/), which permits unrestricted use, distribution, and reproduction in any medium, provided you give appropriate credit to the original author(s) and the source, provide a link to the Creative Commons license, and indicate if changes were made.

\section{References}

Besson J, Aquitaine E. Performance of slanted and horizontal wells on an anisotropic medium. In: SPE European petroleum conference, 21-24 October. The Hague, Netherlands; 1990. doi:10.2118/20965-MS.

Chaperon I. A theoretical study of coning toward horizontal and vertical wells in anisotropic formations: subcritical and critical rates. In: SPE annual technical conference and exhibition, 5-8 October. New Orleans, Louisiana; 1986. doi:10.2118/15377-MS.

Cheng LS. Higher seepage mechanics. Beijing: Petroleum Industry Press; 2011 (in Chinese).

Cheng LS, Lang ZX, Zhang LH. Reservoir engineering problem of horizontal wells coning in bottom-water drive reservoir. J Univ Pet China. 1994;18(4):43-7 (in Chinese).

Dikken BJ. Pressure drop in horizontal wells and its effect on production performance. In: SPE India oil and gas conference and exhibition, 17-19 February. New Delhi, India; 1990. doi:10. 2118/39521-MS.

Dou H, Lian S, Guan C. The experimental studies of physical simulation of bottom water reservoirs with barrier and permeable interbed on horizontal well. In: SPE western regional meeting, 26-27 May. Anchorage, Alaska; 1999. doi:10.2118/55995-MS.

Goode PA, Wilkinson DJ. Inflow performance of partially open horizontal wells. J Pet Technol. 1991;43(8):983-7. doi:10.2118/ 19341-PA.

Guo BY, Molinard JE, Lee RL. A general solution of gas/water coning problem for horizontal wells. In: SPE European petroleum conference, 16-18 November. Cannes, France; 1992. doi:10.2118/25050-MS.

Holmes JA, Barkve T, Lund O. Application of a multi-segment well model to simulate flow in advanced wells. In: European petroleum conference, 20-22 October. The Hague, Netherlands; 1998. doi:10.2118/50646-MS.

Islam MR. Oil recovery from bottom-water reservoirs. J Pet Technol. 1993;45(6):514-6. doi:10.2118/25394-PA. 
Landman MJ, Goldthorpe WH. Optimization of perforation distribution for horizontal wells. In: SPE Asia-Pacific conference, 4-7 November. Perth, Australia; 1991. doi:10.2118/23005-MS.

Li XG, Wang QH, Li Y. Numerical simulation model of perforated well completions. J Univ Pet China. 1996;20(2):48-53 (in Chinese)

Li GS, Song J, Xiong W, et al. Simulation model and calculation of seepage flow field for high pressure waterjet perforated wells. Pet Explor Dev. 2006;32(6):97-100 (in Chinese).

Li H, Chen DC, Meng HX. Optimized models of variable density perforation in the horizontal well. Pet Explor Dev. 2010;37(3): 363-8 (in Chinese)

Luo X, Jiang L, Su Y, Huang K. The productivity calculation model of perforated horizontal well and optimization of inflow profile. Petroleum. 2015;1(2):154-7. doi:10.1016/j.petlm.2015.04.002.

Muskat M, Wycokoff RD. An approximate theory of water-coning in oil production. Trans AIME. 2013;114(1):144-63. doi:10.2118/ 935144-G.

Novy RA. Pressure drops in horizontal wells: when can they be ignored. SPE Reserv Eng. 1995;10(1):29-35. doi:10.2118/ 24941-PA.

Ouyang LB, Huang B. A comprehensive evaluation of well-completion impacts on the performance of horizontal and multilateral wells. In: SPE annual technical conference and exhibition, 9-12 October. Dallas, Texas; 2005. doi:10.2118/96530-MS.

Pang W, Chen DC, Zhang ZP, et al. Segmentally variable density perforation optimization model for horizontal wells in heterogeneous reservoirs. Pet Explor Dev. 2012;39(2):230-8. doi:10. 1016/S1876-3804(12)60036-6.

Penmatcha VR, Arbabi S, Aziz K. A comprehensive reservoir/ wellbore model for horizontal well. In: SPE India oil and gas conference and exhibition, 17-19 February. New Delhi, India; 1998. doi:10.2118/39521-MS.

Permadi P, Lee RL, Kartoatmodjo RST. Behavior of water cresting under horizontal wells. In: SPE annual technical conference and exhibition, 22-25 October. Dallas, Texas; 1995. doi:10.2118/ 30743-MS.

Permadi P, Gustiawan E, Abdassah D. Water cresting and oil recovery by horizontal wells in the presence of impermeable streaks. In: SPE/DOE improved oil recovery symposium, 21-24 April. Tulsa, Oklahoma; 1996. doi:10.2118/35440-MS.

Sognesand S, Skotner P, Hauge J. Use of partial perforations in Oseberg horizontal wells. In: SPE annual technical conference and exhibition, 25-28 September. New Orleans, Louisiana; 1994. doi:10.2118/28569-MS.

Su Z, Gudmundsson JS. Pressure drop in perforated pipes: experiments and analysis. In: SPE Asia Pacific oil and gas conference, 7-10 November. Melbourne, Australia; 1994. doi:10.2118/ 28800-MS.

Umnuayponwiwat S, Ozkan E. Water and gas coning toward finiteconductivity horizontal wells: cone buildup and breakthrough. In: SPE rocky mountain regional/low-permeability reservoirs symposium and exhibition, 12-15 March, Denver, Colorado; 2000. doi:10.2118/60308-MS.

Wang $\mathrm{RH}$, Zhang $\mathrm{YZ}, \mathrm{Bu} \mathrm{YH}$, et al. A segmentally numerical calculation method for estimating the productivity of perforated horizontal wells. Pet Explor Dev. 2006;33(5):630-3 (in Chinese).

Wibowo W, Permadi P, Mardisewojo P, et al. Behavior of water cresting and production performance of horizontal well in bottom water drive reservoir: a scaled model study. In: SPE Asia Pacific conference on integrated modelling for asset management, 29-30 March, Kuala Lumpur, Malaysia; 2004. doi:10. 2118/87046-MS.

Xiong J, He HP, Xiong YM, et al. The effect of partial completion parameters in horizontal well on water coning. Nat Gas Geosci. 2013;24(6):1232-7 (in Chinese).

Yuan H, Sarica C, Brill JP. Effect of perforation density on single phase liquid flow behavior in horizontal wells. In: SPE international conference on horizontal well technology, 18-20 November, Calgary, Alberta, Canada; 1996. doi:10.2118/37109MS.

Zhao G, Zhou J, Liu X. An insight into the development of bottom water reservoirs. J Can Pet Technol. 2006;45(4):22-30. doi:10. 2118/06-04-CS.

Zhou ST, Ma DQ, Liu M. Optimization of perforation tunnel distribution in perforated horizontal wells. J China Univ Pet (Ed Nat Sci). 2002;26(3):52-4 (in Chinese). 